\title{
El puñal Monte Bernorio de la tumba 32 de la necrópolis de Las Ruedas ¿arma y objeto de veneración de los antepasados? Nueva propuesta sobre la iconografía desarrollada en su pomo
}

\author{
The Monte Bernorio dagger from tomb 32 of the Las \\ Ruedas necropolis. Weapon and object of veneration \\ of the ancestors? New proposal on the iconography \\ developed on its pommel
}

\author{
Roberto De Pablo Martínez \\ Universidad de Valladolid \\ roberto_de_pablo@hotmail.com \\ ORCID iD: https://orcid.org/0000-0001-9966-8382
}

Enviado: 13-04-2020. Aceptado: 13-10-2020. Publicado online: 07-07-2021

Cómo citar este artículo / Citation: De Pablo Martínez, R. (2021). "El puñal Monte Bernorio de la tumba 32 de la necrópolis de Las Ruedas ¿arma y objeto de veneración de los antepasados? Nueva propuesta sobre la iconografía desarrollada en su pomo". Archivo Español de Arqueología, 94, e12. DOI: https://doi.org/10.3989/ aespa.094.021.12

RESUMEN: Tres décadas después del descubrimiento de la tumba 32 de Las Ruedas reinterpretamos el significado de la iconografía desarrollada en el reverso del pomo que allí se encontró a la luz de los nuevos datos, interpretaciones y estudios sobre diferentes ámbitos de la cultura vaccea que se puedan ver relacionados con la iconografía ahí desarrollada. Comenzamos con una revisión de las figuras representadas, después damos una explicación a las mismas de forma individualizada, para, finalmente, hacer una lectura de forma conjunta de la escena.

Palabras clave: armas; vacceos; Segunda Edad del Hierro; Las Ruedas; combate singular; zoomorfo; buitre.

ABSTRACT: Three decades after the discovery of tomb 32 in Las Ruedas cemetery, we have reinterpreted the meaning of the iconography developed on the reverse side of the pommel found there. The iconography has been studied with the help of new data and new interpretations and studies regarding different issues of the Vaccaean culture. We commence with a review of the figures represented and proceed with an individually explanation of each of them, to conclude with a compilation reading of the scene.

Keywords: weapons; vaccean; Second Iron Age; Las Ruedas; monomachia; zoomorphic; vulture.

Copyright: (C) 2021 CSIC. Este es un artículo de acceso abierto distribuido bajo los términos de la licencia de uso y distribución Creative Commons Reconocimiento 4.0 Internacional (CC BY 4.0). 
La tumba número 32 de la necrópolis de Las Ruedas (Padilla de Duero/Peñafiel, Valladolid) fue descubierta en 1986 en la que era la tercera campaña de excavaciones en la Zona Arqueológica de Pintia. Esta tumba, alterada por las labores agrícolas practicadas en los años previos en el cementerio, conservaba in situ la urna cineraria y, sobre ella, varios objetos de un ajuar de guerrero pertenecientes al difunto (Sanz, 1997, pp. 85-89) (Fig. 1). Estos objetos constituían una panoplia incompleta, de la que solo quedaba una grapa de caetra y el pomo y el broche de un puñal de tipo Monte Bernorio ${ }^{1}$, quedando de esta manera ausentes otras partes del conjunto del puñal, como la

1 Los puñales Monte Bernorio han sido estudiados desde principios del siglo XX por varios autores, destacando los trabajos de Juan Cabré (1931), Beatriz De Griño (1989) y Carlos Sanz (1990), a los que se unen las aportaciones de otros investigadores como Idoia Filloy y Eliseo Gil (1997). Recientemente hemos sido nosotros mismos quienes hemos hecho un trabajo monográfico dedicado a este tipo de puñal (De Pablo, 2018, pp. 65-345).
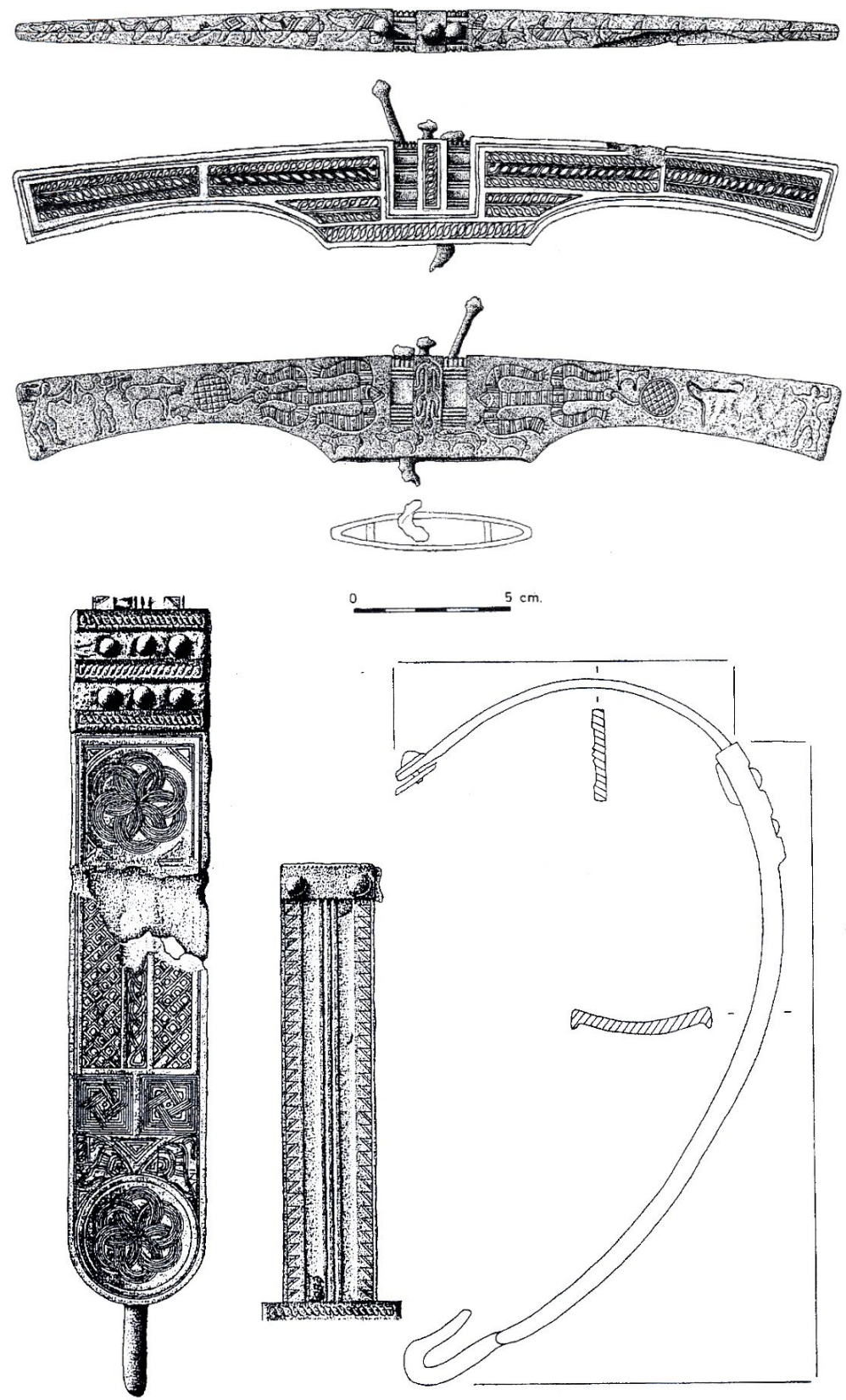

Figura 1. Pomo y broche de tipo Monte Bernorio de la tumba 32 de Las Ruedas (según Sanz, 1997, figs. 77-78). 
hoja y la guarda, así como la vaina. La excepcionalidad de la tumba y el interés que rápidamente despertó se debieron a las representaciones figuradas existentes tanto en el broche como, sobre todo, en el pomo.

Qué duda cabe que el hallazgo de estas dos piezas constituía toda una novedad, ya que casi cien años después del descubrimiento del primer puñal por parte de Romualdo Moro en el yacimiento epónimo del Monte Bernorio y con casi un centenar de piezas conocidas, ninguno de ellos había revelado una decoración figurada. Hasta ese momento, la fascinación que tenían muchos investigadores por estas dagas se debía, tanto a su singular morfología como a una decoración extremadamente compleja, la cual, sin embargo, se ceñía únicamente a representar motivos geométricos.

\section{LA ESCASA DECORACIÓN FIGURADA EN LOS PUÑALES MONTE BERNORIO}

Aún hoy, tres décadas después de ese descubrimiento, la decoración figurada en los puñales de tipo Monte Bernorio sigue siendo muy escasa. Hasta el momento, solo tres piezas nos han deparado una decoración de estas características, dos de las cuales pertenecen a un mismo conjunto de puñal y son el broche y el pomo de la tumba 32 de Las Ruedas, que hemos mencionado arriba, y la tercera es un broche hallado en prospección en la necrópolis de Piñuelas del poblado de La Hoya (Laguardia, Álava) (De Pablo, 2018, cat. 109).

La pieza de Piñuelas es un broche que solo conserva la parte central, faltándole tanto el remate distal con el gancho como el proximal donde se suele colocar la presilla. Está formado por una base de hierro en la que se desarrolla una decoración damasquinada en hilo de plata con motivos geométricos. El ornamento damasquinado está enmarcado por listones de bronce moldurados con acanaladuras y, precisamente, en esta parte del broche es donde encontramos esa tan singular decoración figurada de la pieza. Esta consiste en cabezas zoomorfas, que hemos identificado con lobos, cuya morfología puede ser de tres tipos diferentes tal y como se observa en las fotografías que presentamos de esta pieza hasta el momento inédita (Fig. 2).

Las otras dos piezas (broche y pomo) con decoración figurada son las halladas en el ajuar funerario de la tumba 32 de Las Ruedas. La decoración del broche $\mathrm{y}$, sobre todo, la del pomo fueron estudiadas por Carlos Sanz en su estudio monográfico sobre dicha necrópolis vallisoletana (Sanz, 1997, pp. 439-448), quien no solo se ciñó a hacer una descripción del ornato de esas extraordinarias piezas, sino que intentó llevar a cabo una interpretación de lo allí representado. Sin duda, la pieza que más interés ofrece es el pomo por el gran número de figuras en él representadas además
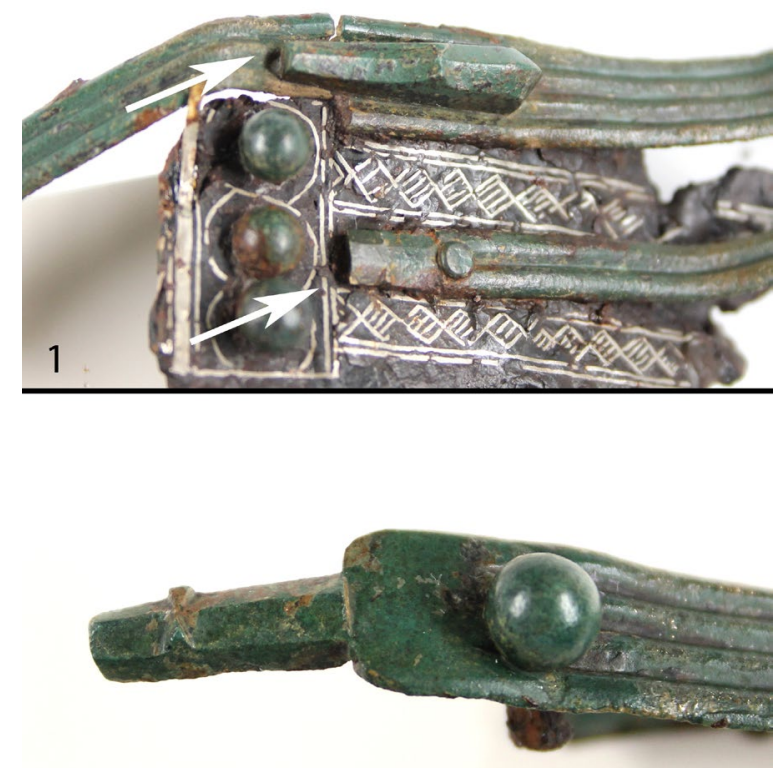

2

Figura 2. Broche hallado en prospección en la necrópolis de Piñuelas. Detalle de la decoración con los tres tipos de cabezas de lobo (fotografías del autor).

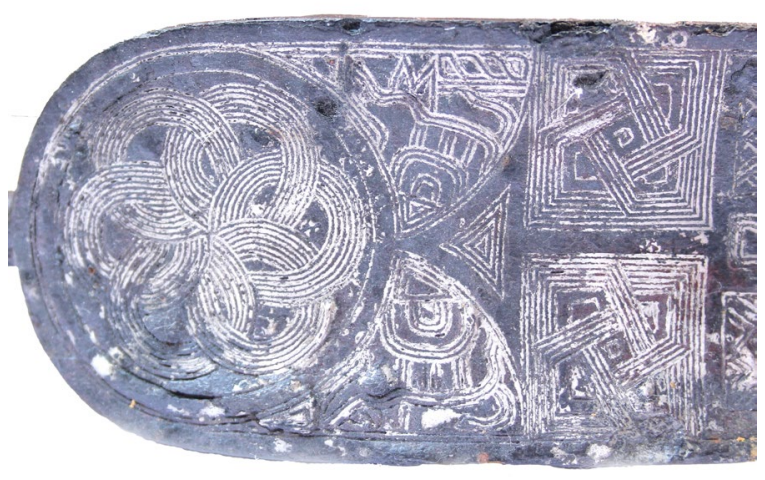

Figura 3. Zoomorfos del broche de la tumba 32 de Las Ruedas (fotografía del autor).

de por su temática, si bien, el broche también tiene un gran valor a la hora de llevar a cabo ciertas interpretaciones sobre la decoración del conjunto.

El broche muestra una superficie completamente decorada con bandas horizontales donde se desarrollan motivos geométricos como lacerias, rombos entrelazados o triángulos encadenados, todo ello damasquinado en hilo de plata. En la parte distal del broche se disponen dos zoomorfos vistos de perfil (Fig. 3), a cuerpo completo, de los que destaca, sobre todo, una larga cola, un hocico muy prolongado hacia arriba 

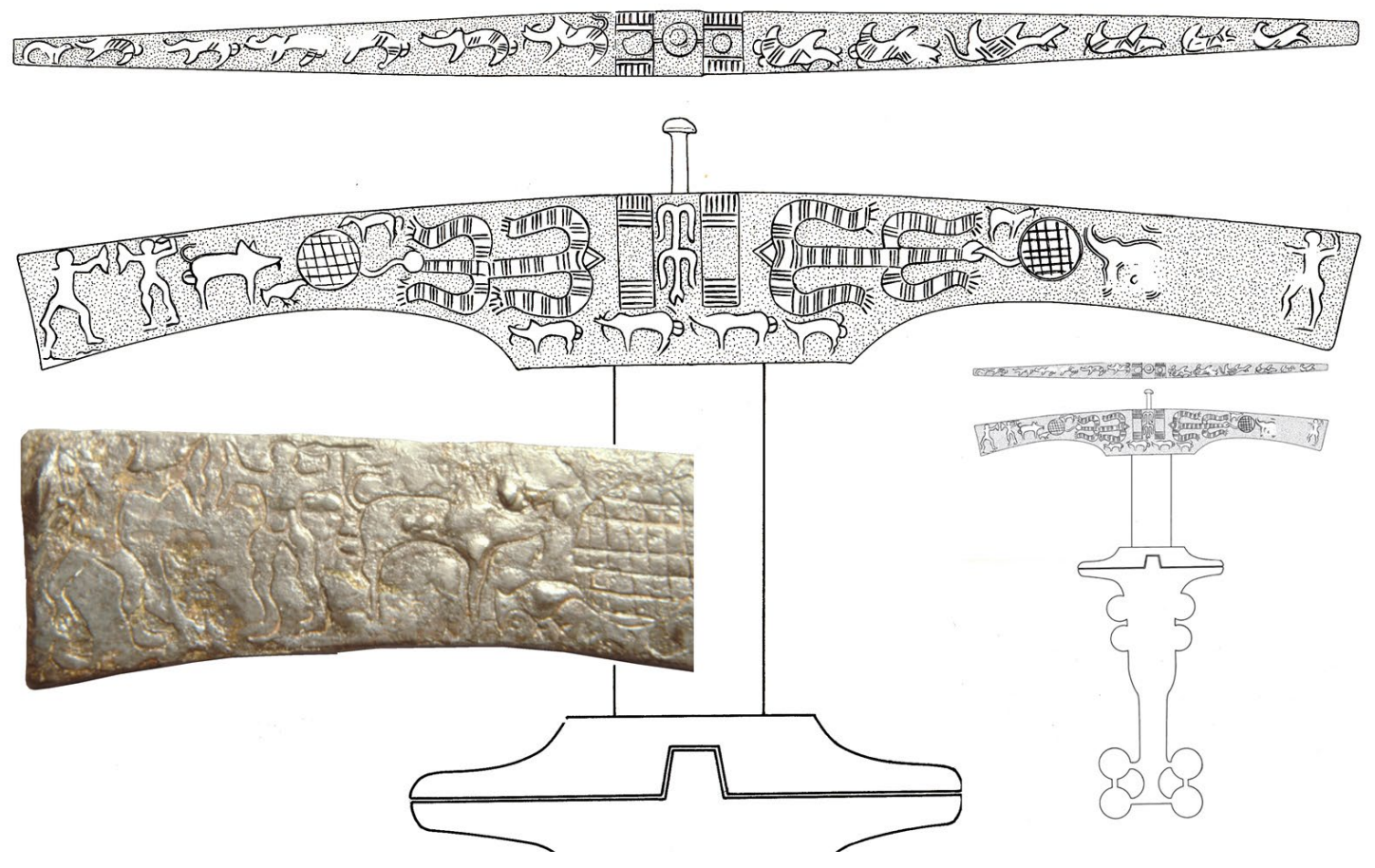

Figura 4. Pomo de la tumba 32 de Las Ruedas (según Sanz, 2010, fig. 18).

y unas orejas picudas. Estos dos zoomorfos fueron interpretados por Sanz como dos verracos (1997, p. 440) sin más explicación del porqué. A nuestro juicio, a tenor de la cola podrían considerarse como tales y más en concreto como jabalíes, sobre todo, por su parecido con los jabalíes representados en el pomo. Sin embargo, la ausencia de colmillos (que sí tienen los del pomo y muy destacados) y la presencia de orejas picudas nos llevan a sopesar la posibilidad que estos dos zoomorfos fueran cánidos, y concretamente lobos, los cuales parecen estar en una posición de aullido.

El pomo de la tumba 32 de Las Ruedas, y concretamente la cara del reverso y el canto superior, constituye el marco donde se contabilizan un total de 24 animales a los que hay que añadir dos parejas de guerreros enfrentados (Figs. 4 y 5). Los jabalíes predominan en la escena con 17 ejemplares $^{2}$, a los que se suman dos caprinos o équidos ${ }^{3}$, un ave, un cánido

2 Algunas de las representaciones de la parte inferior del pomo podrían interpretarse como bóvidos, pero los rasgos de los dos animales de mayores dimensiones parecen asemejarlos más a jabalíes.

3 Sanz reconoce en estos animales ovicápridos. Lo cierto es que el poco espacio que se deja para la representación de estos dos animales hace que se observen algunas limitaciones propias de la técnica y el marco. En nuestra opinión, los dos animales representados podrían ser caprinos, sin embargo, como luego explicaremos nos decantamos por pensar que son équidos. $\mathrm{y}$ tres zoomorfos en perspectiva cenital que podemos interpretar como cánidos. Por su parte, la distribución de estas figuras, fue narrada perfectamente por Sanz,

se realizó siguiendo una evidente simetría, constituyendo el pequeño cenital de disposición vertical situado en la mitad del pomo el eje a partir del cual se plasmaron a un lado y a otro, idénticos motivos. Existen, sin embargo, ciertas alteraciones en ambas mitades que impiden hablar de una simetría perfecta. Así, en el lado izquierdo, bajo el verraco de mayor tamaño inmediato a los guerreros, se incluyó una pequeña ave inexistente en el lado contrario; por su parte en este el círculo reticulado y el verraco mayor son los dos únicos elementos que han sido delineados en trazo doble; finalmente en el canto llama la atención la disposición inversa de los animales de un lado con respecto a los otro, así como la presencia de un verraquito más en el lado izquierdo que en el derecho [...] y muy particularmente la sustitución en el lado izquierdo del tercer verraquito por un cánido (Sanz, 1997, p. 440).

Finalmente, a estas anomalías vistas por Sanz añadimos una a mayores: los dos animales representados en perspectiva cenital no son exactamente iguales, mientras que el de la parte izquierda no tiene representadas las fauces y presenta dos prolongaciones a los lados a modo de cuernos u orejas, el de la parte 


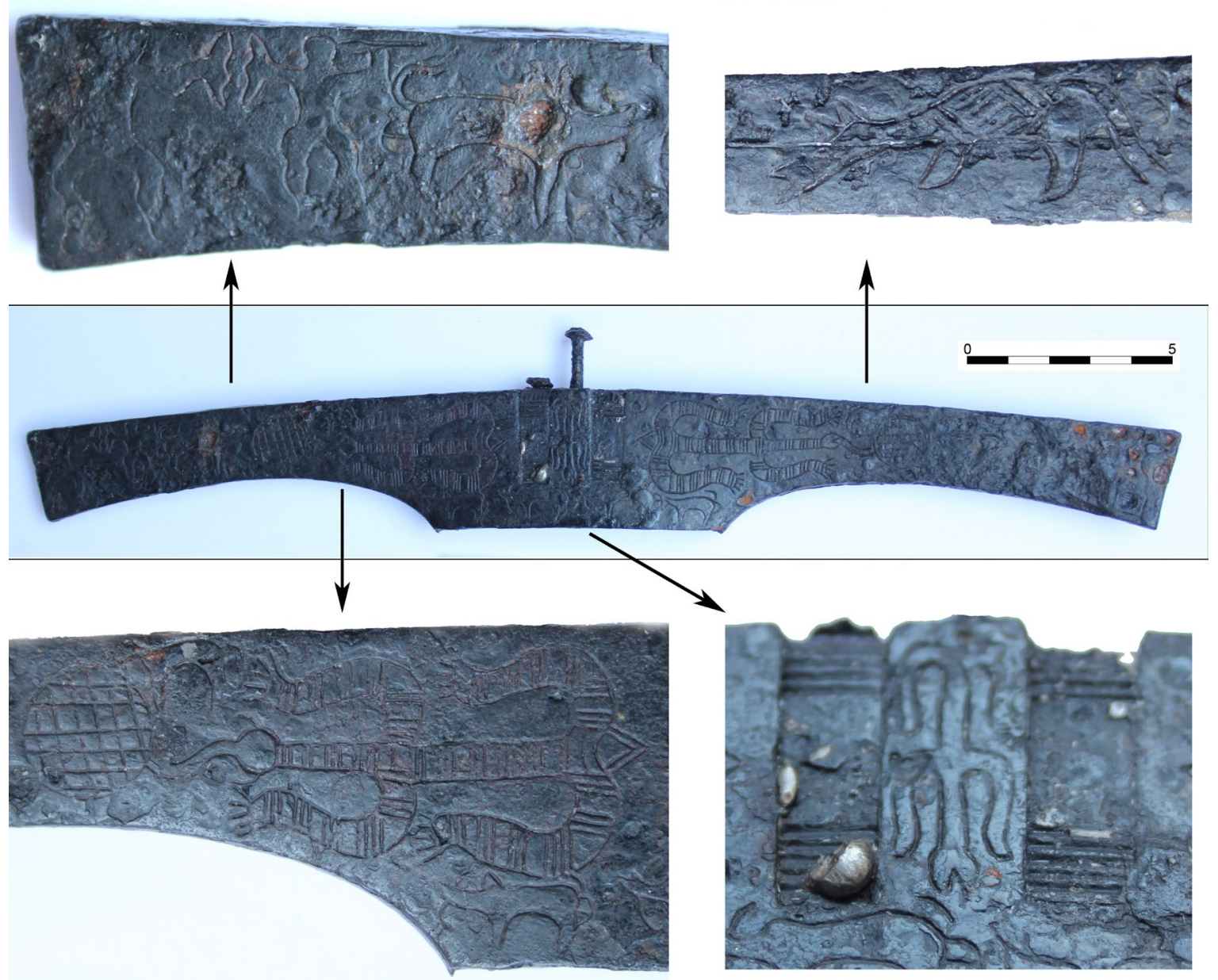

Figura 5. Pomo de la tumba 32 de Las Ruedas. En detalle se han extraído cuatro imágenes: el combate singular y el verraco del extremo izquierdo del pomo (arriba a la izquierda); animal en perspectiva cenital con circulo reticulado y caballo del lado izquierdo del pomo (abajo a la izquierda); perro del canto superior del pomo (arriba a la derecha); y animal en perspectiva cenital sin lengua ni círculo reticulado (abajo a la derecha) (elaboración propia y fotografias del autor).

derecha tiene las fauces abiertas y no tiene esas dos prolongaciones laterales.

La interpretación de los animales por nuestra parte va en la misma línea que la lectura y el reconocimiento hecho por C. Sanz de la mayoría de los animales representados en el pomo, sin embargo, no coincidimos completamente con la interpretación de cada una de las figuras. Por ello llevaremos a cabo una revisión de los animales ahí representados.

Comenzando por los verracos o jabalíes, estos como decimos, son los más numerosos en el pomo, apareciendo un total de 11 en el canto y 6 en el reverso. Estos 17 animales fueron interpretados por Sanz como verracos, algo que podríamos compartir (Fig. 5) a tenor del parecido de algunos de los ejemplares con algunas fíbulas con puente en forma de verraco. En palabras de Sanz:
La representación de estos verracos centra su interés en destacar determinados detalles anatómicos que se repiten sistemáticamente en todos y cada uno de los individuos existentes [...] todos ellos muestran una puntiaguda cabeza con el hocico abierto conformado en $\mathrm{M}$ y, en una posición ligeramente atrasada, sendos colmillos hacia arriba y hacia abajo; se destacan asimismo las orejas en forma de trazo triangular $[\ldots]$ un rabo corto levantado [...], aunque no tanto como se podría esperar para esta especie, y bajo éste unas abultadas gónadas masculinas en forma de pequeño semicírculo adosado a los cuartos traseros y dividido a la mitad que parecen querer expresar sin equívocos ambos testículos; finalmente, las patas conforman dos pequeños apéndices puntiagudos (Sanz, 1997, p. 446).

A tenor de los rasgos vistos por Sanz y, sobre todo, teniendo en cuenta el número de representaciones de 
jabalíes o verracos en la plástica prerromana, interpretamos estas figuras como verracos. Al respecto de este último, el registro arqueológico meseteño ha deparado un buen número de representaciones de verracos en la iconografía prerromana $\mathrm{y}$, en concreto, en el ámbito vacceo ${ }^{4}$, donde podemos poner como ejemplo desde las "fíbulas de verraco" de Paredes de Nava (Schüle, 1969, taf. 164.10-164.11) hasta una cabeza de jabalí de bulto redondeo modelada en arcilla hallada en el yacimiento de La Guadaña (Blanco, 2014, p. 199). Asimismo, en el vecino mundo vetón, el jabalí adquiere incluso un mayor relieve, es más, de sobra son conocidas las representaciones de jabalíes en las esculturas graníticas del llamado foco vetón (Álvarez-Sanchís, 1990).

Los dos siguientes animales a interpretar se disponen junto al círculo reticulado de los dos zoomorfos en perspectiva cenital (Fig. 5); ahí encontramos las dos representaciones que fueron interpretadas como cápridos por Sanz, "una corta cola y una cabeza en la que se indica una breve cornamenta así lo sugieren" (Sanz, 1997, p. 447). En nuestra opinión, no podemos descartar que el artesano quisiera representar caprinos en el pomo, sin embargo, la afirmación de Sanz sobre la cola, a nuestro juicio, no es del todo acertada, ya que el ejemplar situado en la izquierda del pomo tiene una larga cola cuyo trazado parece asemejarse más a la de un équido. Así, la cola de los équidos suele hacer una larga curvatura hacia abajo, en tanto que las cabras suelen tener una corta cola que se orienta hacia arriba. Por su parte, la cornamenta a la que alude Sanz como segunda evidencia para identificarlos como cabras, puede no ser más que las dos orejas puntiagudas de un caballo, dado el corto trazado de las mismas. También es cierto que los caprinos son animales muy poco representados en la iconografía de la zona ${ }^{5}$, por el contrario, de todos es sabido que los équidos son muy abundantes ${ }^{6}$, tanto solos como acompañados de

4 Blanco en una de sus últimas publicaciones afirmaba que las representaciones de los suidos en el mundo vacceo ocupan un lugar muy destacado (2014, pp. 197-199) algo que compartimos.

5 Es cierto que se han encontrado algunas representaciones de carneros en la iconografía vaccea (Blanco 2013, pp. 58-59; Sanz y Blanco, 2015), que no de cabras. Si hablamos de ovicapridos podemos incluir varios ejemplares dentro de la iconografía de la zona estudiada, como la cajita con cabeza de carnero de la tumba 153 de Las Ruedas. Sin embargo, si hablamos de caprinos estrictamente solo se ha propuesto, aparte de los animales que tratamos, una copa de anillas de Palencia en la que aparecen cabezas con cuernos de las que se ha apuntado la posibilidad de que se traten de toros o cabras (Lión, 1987, pp. 18, 29, nº 3; Blanco, 2013, pp. 57-59).

6 A este respecto el artículo de S. Alfayé es muy ilustrativo; en las tablas de animales representados (2010, tabla II y IV) se observa un claro predominio del caballo por encima de todos los demás y en particular sobre los ovicápridos.

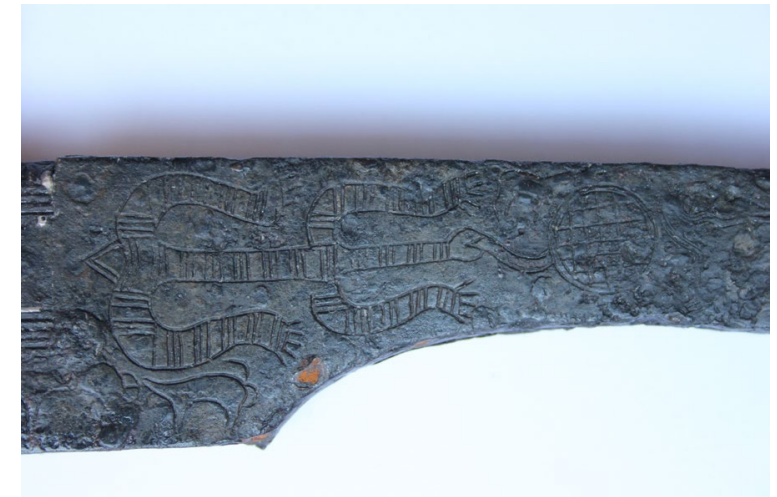

Figura 6. Zoomorfo en perspectiva cenital del pomo de la tumba 32 de Las Ruedas, en concreto el situado a la derecha de la escena (fotografía del autor).

un jinete. Así lo demuestran, entre otras muchas, las conocidísimas fíbulas de caballito, extendidas no solo por el territorio vacceo sino por toda la meseta norte, los mangos de simpula hallados en la necrópolis de $\mathrm{La}$ Alcántara (Martín Valls, 1990, pp. 153-155, fig. 1 y 2.4) o en Las Ruedas (Sanz y Blanco, 2015, 62, núm. 1.4.1 y 1.4.2), los numerosos caballos representados con pintura en la cerámica torneada de cocción oxidante (Alfayé, 2010, tabla II; Blanco, 2013, pp. 55-56; Sanz y Blanco, 2015, pp. 58-62) o Duero abajo, las numerosas representaciones de caballos en las rocas de Foz Coa, tanto solos (Luis, 2016, pp. 65-66) como vinculados a un jinete (Luis, 2016, pp. 65-69). Por todo ello nos decantamos por pensar que las representaciones de animales situadas junto a ese círculo o torta reticulada son caballos y no cabras.

El pomo muestra además un cánido en el canto superior (Fig. 5). En este caso, coincidiendo también esta vez con Sanz, es evidente que estamos ante un perro, en el que se destacan unas fauces donde se han marcado los dientes, unas orejas apuntadas (están representadas las dos) y una cola larga de doble trazo. El animal parece disponerse en una posición amenazante o agresiva dado que tiene hocico hacia abajo y enseñando los dientes.

Rompiendo la simetría del reverso del pomo encontramos un ave, de difícil asignación, y aún más cuando esa parte precisamente esta afectada por la oxidación y la corrosión. Sanz destacó de ella "una cola trapezoidal, un cuerpo fusiforme, algo pesado, con la cabeza orientada hacia el suelo en actitud de picotear, y dos patas con sus correspondientes dedos" (Sanz, 1997, p. 448), lo que le llevó a reconocer en el ave una perdiz o, más bien, una gallina. Ciertamente es muy complicado reconocer qué ave se quiso representar en nuestro pomo. No podemos descartar que se trate de una gallina o incluso de una perdiz, sin embargo, el principal problema que vemos 

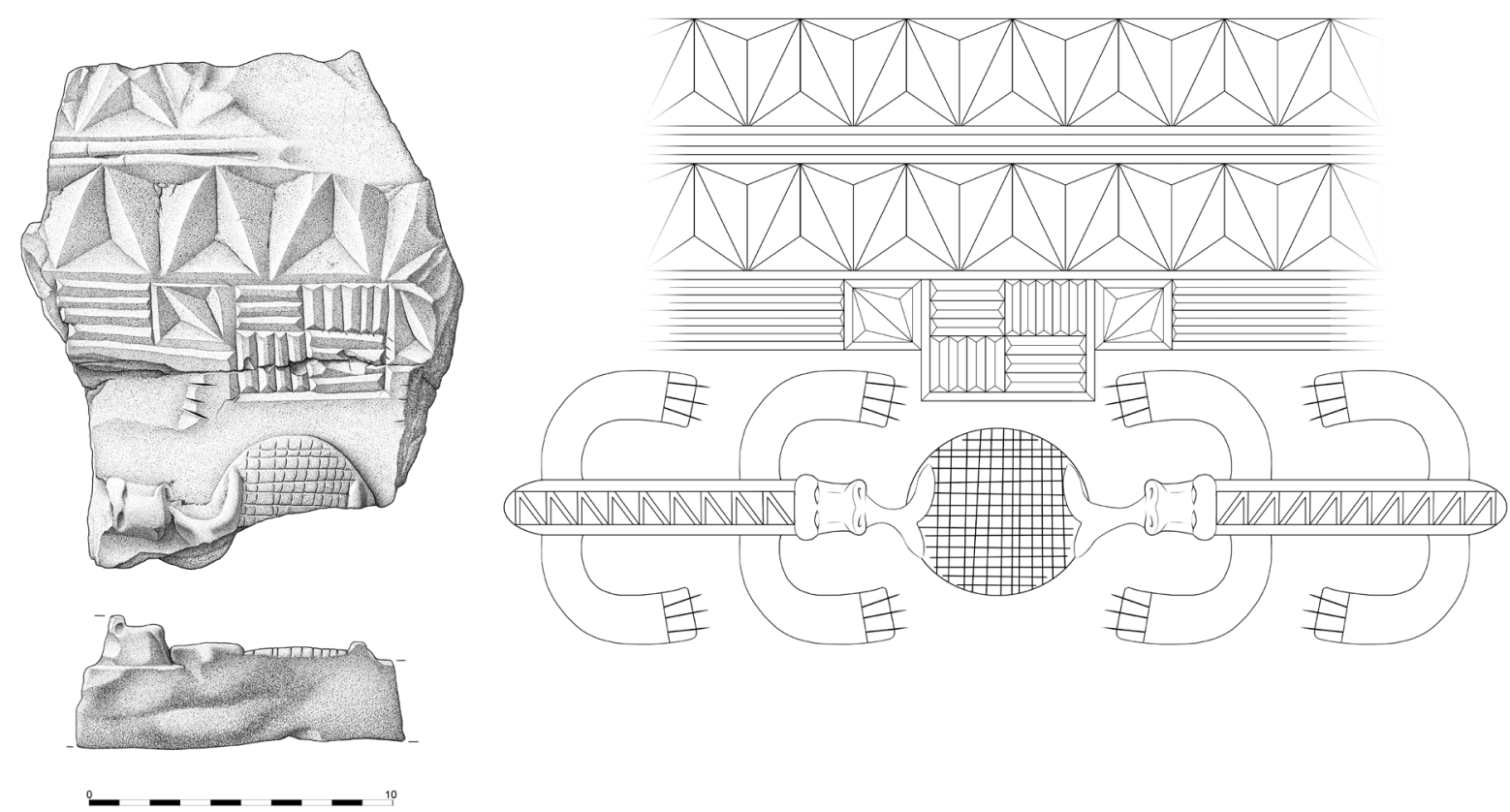

Figura 7. Placa con decoración aplicada de un animal representado en perspectiva cenital e identificado con un lobo, procedente de El Villar, y reconstrucción hipotética de los dos animales completos. Dibujo de Francisco Tapias (según Romero y De Pablo, 2019, fig. 22).

es que el mundo prerromano meseteño y en concreto el vacceo no parece darle una gran relevancia a esta ave, dado que la presencia de estos animales se ciñe a pocos restos de gallinácea en las ofrendas de algunas tumbas pintianas (Sanz, 1997, p. 448). De la misma forma, hablar de la importancia del gallo como ofrenda en la Galia céltica no deja de ser cuando menos arriesgado, tanto por la distancia que separa una y otra región, como por las diferencias en la cultura material, y sobre todo, por erigir nuevamente nuestra región en deudora de la Galia. Bajo nuestro punto de vista, el animal representado no es una gallina ni una perdiz, sino que es una de las aves más citadas en relación con los pueblos prerromanos de la meseta norte. Nos referimos, indudablemente, al buitre. Los vultúridos presentan una morfología que encaja muy bien con la figura del pomo y este podría estar representado en la posición de comer, como ave carroñera que es. La interpretación de esta ave como un buitre cuenta con más respaldo en el registro arqueológico, tal y como lo demuestran, entre otros objetos arqueológicos, la chapita de bronce con forma de cabeza de buitre hallada en Las Ruedas (Sanz, 2010, fig. 16), las conocidísimas cerámicas numantinas o la estela de Zurita, donde encontramos las similitudes más cercanas con el buitre representado en nuestro pomo.

Por su parte, los animales en perspectiva cenital podrían considerarse, sin lugar a dudas, los más complicados de interpretar (Fig. 5 y 6). En el momento de su hallazgo, se apuntó que estos tres zoomorfos pudieran ser cánidos a partir de sus rasgos anatómicos (Sanz, 1997, p. 442), algo que se confirmó, años después, con el descubrimiento de "El Vaso de los Lobos" en la casa del sótano en el yacimiento burgalés de Las Eras de San Blas de Roa (Abarquero, 2006-2007). Recientemente, han sido varios los hallazgos de zoomorfos representados en perspectiva cenital con la lengua conectada a un círculo reticulado los que han venido a confirmar la interpretación de estos animales como cánidos: dos de ellos proceden de la necrópolis de Las Ruedas. El primero consiste en un cenital pintado bajo el borde de un vaso de cerámica (Sanz y Blanco, 2015, cat. 1.2.33) y el segundo es un aplique broncíneo (Sanz y Blanco, 2015, cat. 2.3.9); otro más lo encontramos en una de las placas halladas en el sitio fortificado del Castelinho (Felgar, Torre de Moncorvo, Portugal) (Santos et al., 2012, p. 177, fig. 21); a estos se suman dos piezas más dadas a conocer en los últimos años, una sin contexto preciso y otra procedente de Coca (Almagro-Gorbea, Ballester y Turiel, 2017, pp. 158-162), muy similares ambas a la última pieza de bronce de Pintia; y, finalmente, un ejemplar (Fig. 7) formando parte de la decoración de las placas y bloques prismáticos cerámicos procedentes del yacimiento de El Villar (Bobadilla, La Rioja) y que recientemente hemos dado a conocer (De Pablo, 2018, pp. 258-259, fig. 2.128; Romero y De Pablo, 2019, pp. 125 y 126, fig. 21 y 22). La imagen de estos animales en perspectiva cenital se ha interpretado en varias ocasiones 
como representación o símbolo de una divinidad de carácter protector (Blanco, 1997, pp. 194-198; Sanz, 1997, pp. 439-448; Abarquero, 2006-2007; Romero, 2010, pp. 526535; Abarquero y Palomino, 2012, p. 157; Sanz y Blanco, 2015, p. 52), algo que compartimos y más a partir del hallazgo de esta última representación en unos bloques y placas que muy probablemente revistieron un edificio de corte cultual (Romero y De Pablo, 2019, p. 130).

Finalmente, en los extremos del reverso del pomo, encontramos dos parejas de guerreros enfrentados en lo que parece un combate singular. Los guerreros, representados de perfil, van armados con una lanza, levantada sobre sus cabezas, y un escudo en el que se ha representado el umbo central y la curvatura hacia el exterior (o cóncavo al exterior), una característica de los escudos de tipo Monte Bernorio, típicos de la zona y extendidos por toda la meseta norte. Lo cierto es que, hasta la fecha, las representaciones de combates singulares son bastante escasas. En la meseta el más conocido de todos es el combate singular representado en el llamado "Vaso de los Guerreros" de Numancia (Romero, 1999). Casi tan conocido como el vaso numantino es el broche de la sepultura II del túmulo $\mathrm{Z}$ de la Zona I de La Osera (Cabré, 1937, lám. XXIII; Baquedano y Escorza, 1996, p. 31), el cual, tal vez, muestra la representación más parecida a las del pomo de la tumba 32 de Las Ruedas, puesto que los dos guerreros están representados de perfil, armados con escudos cóncavos al exterior y con una lanza en la mano contraria. A estas representaciones, recientemente, se han sumado otras de Foz Coa. De todas ellas la Roca 3 de Vermelhosa (Luis, 2016, figs. pp. 65.2 y 69), con dos guerreros enfrentados en la parte baja de la misma, es la que más interés ofrece, no solo por estar representados dichos guerreros con las mismas armas que los del pomo, sino también por poseer en la cintura, el contrincante de la derecha, lo que hemos interpretado como un puñal Monte Bernorio con el pomo totalmente desarrollado. Asimismo, en la representación tampoco se nos escapa la presencia, bajo los pies de los combatientes, de dos aves comiendo, las cuales se han interpretado como buitres, y que nos recuerda en la morfología y posición (cerca de los guerreros) al ave del pomo de Las Ruedas. También en Foz Coa encontramos otras dos representaciones de guerreros enfrentándose, una en la roca 6 de Quinta das Tulhas y otra en la roca 38 de Bulha (Luis, 2016, figs. p. 65).

\section{EN BUSCA DE UNA LECTURA PARA CADA UNA DE LAS FIGURAS DEL POMO DE LA TUMBA 32 DE LAS RUEDAS}

En opinión de C. Sanz, la representación de todos estos animales y de las dos parejas de guerreros enfrentados carecía de afán narrativo, apostando por que se tratase, más que de una escena propiamen- te dicha, de la yuxtaposición de diferentes elementos que no estaban del todo inconexos. A partir de aquí, diferenció tres grupos de representaciones, "la zoomorfa en vista cenital con carácter críptico, y las más naturalistas referentes al combate de guerreros o a los animales de sencilla identificación en vista lateral" para resolver que la iconografía desarrollada en el reverso del pomo representaba tres esferas "lo sagrado, lo guerrero y lo productivo" (Sanz, 1997, p. 440). Esta interpretación fue seguida y aceptada por algunos autores como J. F. Blanco (2014, p. 189), no obstante, tampoco se llegó a hacer una revisión del pomo pintiano que repensara el mensaje que pretendía transmitir la decoración.

Nuestra interpretación de la decoración figurada del pomo difiere de la hecha en su día por Sanz. Es evidente, que reconocer otros animales en algunas figuras, aunque sean pocas, condiciona la lectura del mismo. Bajo nuestro punto de vista, hay que interpretar la decoración figurada del pomo como una escena compuesta por varias imágenes o partes con un significado propio, las cuales, leídas en su conjunto y conectando unas con las otras, nos permiten conocer el mensaje final que el pomo pretendió trasmitir. A continuación, pasaremos a interpretar el significado de cada una de las figuras grabadas en el pomo (y el marco donde se desarrollan) para después proceder a desentrañar, en un último apartado, el mensaje que en él hay grabado, conectando ellas en una lectura global.

Empezando por el marco donde se desarrolla la iconografía, es evidente que estamos delante de uno de los ejemplares más destacados, por no decir el más destacado, de los casi tres centenares de puñales Monte Bernorio documentados hasta la fecha por nosotros mismos en nuestro trabajo de tesis (De Pablo, 2018) 7 . Esta pieza, aunque no tuviera esta rica decoración figurada en el reverso, coloca a su poseedor en la cúspi-

7 Se trata de un puñal y un broche totalmente damasquinados en hilo de plata y, en el caso del broche, chapada en plata la parte proximal. Asimismo, estamos ante el pomo de un puñal Monte Bernorio más ancho de todos, superando los $26 \mathrm{~cm}$, lo que además coloca esta pieza como un puñal de escaso valor funcional. En muchas ocasiones se ha dicho que los Monte Bernorio son puñales poco funcionales y que su valor militar era prácticamente nulo. Es cierto que, si valoramos solamente puñales como este, en los que la longitud del pomo podría llegar a igualar a la de la daga completa, esta afirmación tiene sentido, pero no nos olvidemos de que muchos de los puñales Monte Bernorio no tienen esa morfología ni esas dimensiones tan descompensadas para un arma, ni tan siquiera tienen una decoración que exhibir. La visibilidad de estas piezas por delante de aquellas más sencillas y a la vez más funcionales ha contribuido a crear una imagen que no es del todo cierta. Por lo tanto, estamos ante una pieza muy destacada y poco funcional cuyo mayor valor es el de transmitir el poder de un miembro de la élite en concreto. 
de de la jerarquía social de la época y podríamos decir, sin miedo a equivocarnos, que se trata de un destacado miembro de la elite vaccea. Al igual que la pieza en sí misma, la decoración es una forma de distinción, tiene una función ostentatoria y está realizada para exhibirse ${ }^{8}$. Es por todo ello que creemos que hay que interpretar la pieza desde el prisma de la ideología y las creencias de una persona situada en el punto más alto de la jerarquía social que, seguramente, se sirvió de representaciones reconocibles por una parte o por toda la sociedad frente a la que quería reivindicar su posición.

El grupo más numeroso de animales representados son los jabalíes. En la Céltica europea, como bien recordaba recientemente J. F. Blanco (2014, p. 197), este animal tiene diferentes significados, representando desde el desorden y el caos vinculados a la guerra hasta la fuerza y la potencia sexual. En el mundo grecolatino el jabalí era considerado como el animal a batir en las partidas de caza por lo que simbolizaba lo indómito (Blanco, 2014, p. 198). Si bien a nosotros lo que realmente nos interesa es qué significado pudo tener el jabalí en la meseta norte durante la Segunda Edad del Hierro. Coincidimos con Blanco en ver en el jabalí un símbolo de amistad y protección, como parecen suscribir las téseras de hospitalidad con esta forma (Blanco, 2014, p. 198). A esta interpretación, más amable, se sumaría otra más extendida, en la que la figura del jabalí muy probablemente significara la fuerza, la fiereza, la tenacidad y la resistencia en combate que demostraban estos duros animales en los lances de caza, algo que podría explicar además su aparición en otros soportes como las espadas de tipo Miraveche. Un significado que coincidiría con el que tiene en algunas partes de la Céltica europea o incluso en el mundo grecorromano, algo que no debe de extrañar dado que el comportamiento del animal es el mismo en unos que en otros lugares. Así, la representación de estos animales marca un punto de inicio a la hora de interpretar el pomo del puñal. Vemos en los verracos, representados 17 veces, el animal salvaje, y no doméstico, contra el que el poseedor del puñal pudo haberse enfrentado y derrotado en múltiples ocasiones y en cuya caza se demostraba la pericia y habilidad del combatiente. A la vez, la representación del mismo en el pomo, tendría una clara intención de asumir esas facultades del animal al que respetaba a la vez que te-

8 Como pudimos demostrar en nuestro trabajo (De Pablo, 2018, pp. 567-581) existe una gran diferencia entre los conjuntos de tipo Monte Bernorio con vainas rematadas en uno y cuatro discos, siendo las segundas las más costosas y aquellas que muy probablemente fueron propiedad de la clase más destacada de la sociedad. En este caso el pomo y el broche se ajustan totalmente a un conjunto con una vaina rematada en cuatro discos. mía, para hacerlas propias en futuros lances, ya no con un jabalí, que también, sino con otro combatiente. En este sentido interpretamos los jabalíes como el símbolo que representaría la valentía, el arrojo, la tenacidad o la fuerza del poseedor del puñal y de los guerreros representados en los extremos del pomo.

En el centro del espacio, la hipóstasis de la divinidad tiene una clara finalidad, la de protección y salvaguarda del portador, y constituye, a nuestros ojos, una invocación a esa divinidad profiláctica para que procure por el bienestar del portador del puñal, así como por el de aquellas personas representadas en los combates singulares grabados en los extremos del pomo. A pesar de ser todavía muy escasas las representaciones de esta divinidad, al menos mediante este símbolo tan complejo ${ }^{9}$, dos de ellas -la del vaso de los lobos de Roa y la del fragmento del vaso hallado recientemente en Las Ruedas- aparecen vinculadas a vasos o recipientes de almacenaje lo que reafirmaría el carácter protector de esta deidad, en este caso sobre las bases alimentarias y económicas, algo que podríamos extrapolar al pomo que nos ocupa. Coincidimos con la exégesis de Abarquero ${ }^{10}$ (2006-2007, pp. 197-204 y 206) de considerar esta representación en perspectiva cenital como una hipóstasis de Vaelicus o Vaelico, dada la vinculación de esta deidad con el perro y el lobo por el significado de la raíz de su nombre, "uailo", que en lengua céltica significa perro, lobo, perro lobo ${ }^{11} \mathrm{o}$ "el aullador" (Fernández Gómez, 1973, p. 231; 1995, p. 249; Álvarez-Sanchís, 1999, p. 320; Abarquero, 2006-2007, p. 197; Abarquero y Palomino 2012, p. 148). Asimismo, en la asimilación de esta manifestación de la divinidad a Vaelicus, Abarquero propuso un carácter benefactor y apotropaico para la misma (Abarquero, 2006-2007, pp. 200-201), algo con lo que estamos completamente de acuerdo y encajaría a la perfección con la propuesta interpretativa que estamos haciendo del pomo bernoriano de Pintia. Es más, no hemos de descartar la faceta funeraria de esta deidad para las representaciones de este pomo, sí por el contrario descartamos el carácter infernal o subterráneo que otros le aportan (Fernández Gómez, 1973, p. 231; 1995, p. 249).

9 La complejidad de estas representaciones ha dado pie a que se hayan interpretado como monstruos o seres irreales, fruto de la fusión de cánidos, serpientes y jabalíes, que transcendería la esfera de lo natural y se adentraría en la religiosa (Sanz, 1997, pp. 444-445; Romero, 2010, pp. 484-485).

10 Véase también Abarquero y Palomino (2012, pp. 152-153)

11 La vinculación entre esta deidad y el perro/lobo va mucho más allá del propio significado de la raíz de su nombre, para ello consultar los trabajos de F. Fernández Gómez (1973, pp. 228$231 ; 1995$, pp. 247-250). 


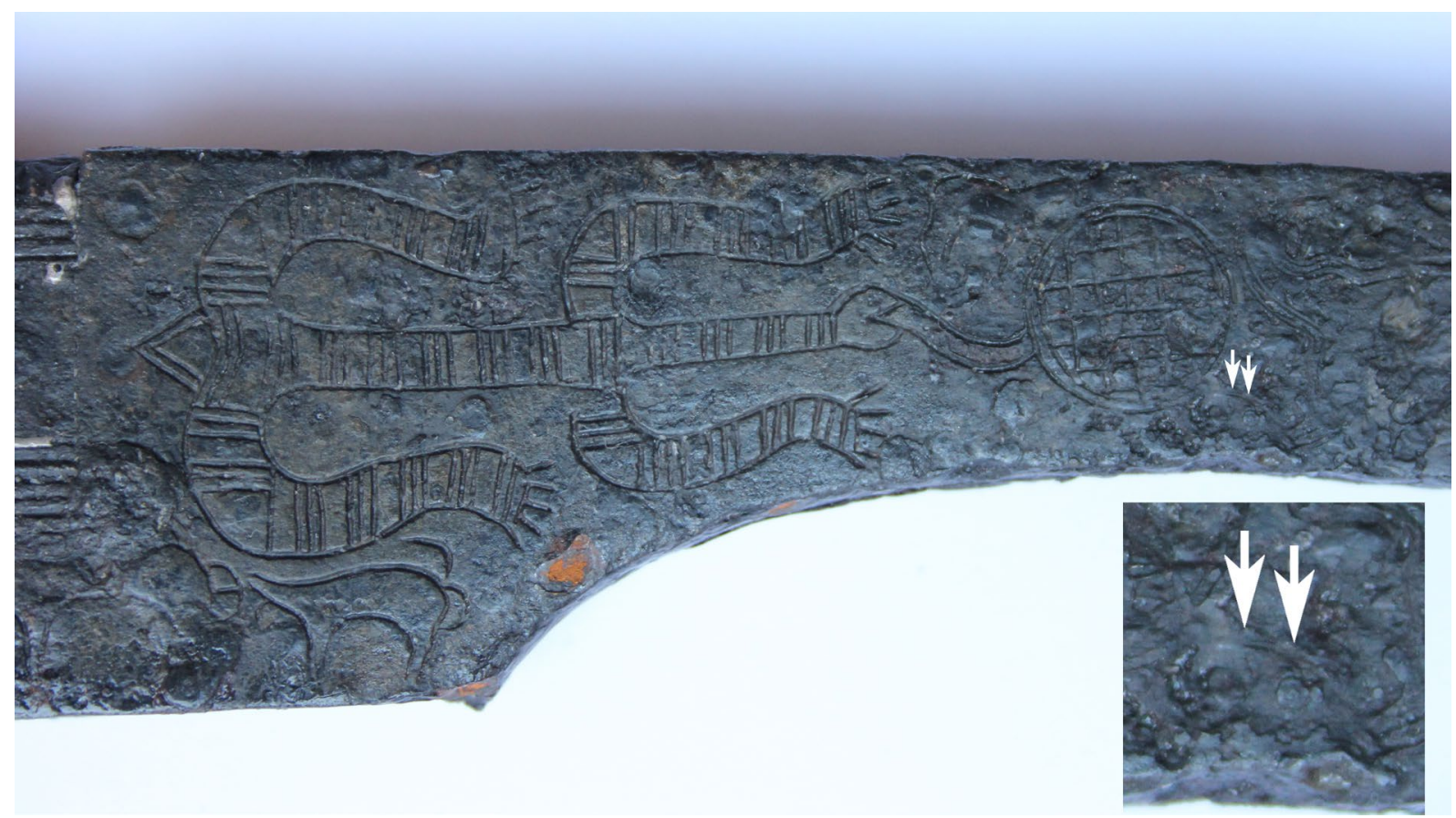

Figura 8. Detalle del espacio bajo el círculo reticulado del zoomorfo de la derecha de la escena, en el que se aprecia un trazo que revelaría la existencia de una nueva figura perdida casi en su totalidad por la oxidación y que comparándola con la contraria podría ser la figura de un buitre (elaboración propia y fotografía del autor).

La aparición de un ave junto a la parte más enigmática de la manifestación de la deidad, el círculo reticulado, pone de relieve la importancia de ese animal en el mensaje que pretende transmitir la escena. A estas alturas, tal y como hemos propuesto líneas atrás, interpretar esta ave como un buitre no es en absoluto descabellado, y menos a tenor de la sabida importancia de este animal en algunos rituales funerarios y el papel que jugaron los vultúridos como psicopompos en el mundo de las creencias de los pueblos prerromanos de la meseta. Sin duda alguna, el texto de Claudio Eliano es el que más atañe al pueblo vacceo:

\begin{abstract}
Los vacceos (pueblo de Occidente) ultrajan a los cadáveres de los muertos por enfermedad, ya que consideran que han muerto cobarde y afeminadamente, y los entregan al fuego; pero a los que han perdido la vida en la guerra, los consideran nobles, valientes y dotados de valor y, en consecuencia, los entregan a los buitres porque creen que éstos son animales sagrados (Claudio Eliano, Natur. anim., X, 22).
\end{abstract}

Esta narración revela que el ritual de exposición de los guerreros muertos en combate a los buitres fue una práctica extendida entre los pueblos de la meseta norte a lo largo de la Segunda Edad del Hierro, es más, especi- fica que dicho ritual estuvo reservado únicamente a los guerreros caídos en combate. El texto se ve respaldado por la existencia de una iconografía que hace referencia a ello en algunos sitios tan distantes como Zurita, donde una estela representa un buitre picoteando el cuerpo de un guerrero yacente, o en Foz Coa, donde en la roca 3 de Vermelhosa se ha representado un combate singular entre dos guerreros y bajo ellos una pareja de buitres están comiendo un cuerpo y que a nuestro juicio debería considerarse como los restos del guerrero caído, después de haber dado cuenta de él los primeros buitres. Por lo tanto, la importancia del buitre en este ritual funerario es evidente, la de ser el transmisor del alma del guerrero entre la esfera terrenal y la celeste y lo creemos bien documentado en la zona que tratamos.

La existencia del ave solo junto a la representación de la divinidad situada a la izquierda del pomo, podría poner en duda que se tratase de tal animal ya que en ese punto parece romperse la estricta simetría del pomo en la cara del reverso. Sin embargo, un análisis visual más pormenorizado de la parte donde debería aparecer la segunda figura de un ave, ha revelado la existencia de varios trazos que confirman que en ese punto hubo otra figura de difícil adscripción (Fig. 8), aunque dada la lógica de la simetría, podríamos concluir que se trata de otro buitre, lo que elevaría finalmente el número de animales representados, ahora sí, a 25. 
En los extremos del pomo nos encontramos esas dos parejas de guerreros combatiendo en lo que ha de interpretarse como dos combates singulares bien documentados en el mundo prerromano de la zona de la meseta, tanto en la iconografía, tal y como hemos dicho más arriba, como en las fuentes clásicas. En este caso, no solo queremos interpretar estas dos monomaquias como tales, sino que nos gustaría ir un poco más allá $\mathrm{y}$, al hilo de lo dicho con respecto al marco en el que inscribe la decoración figurada, proponer este tipo de enfrentamientos particulares como una actividad propia y exclusiva de miembros pertenecientes a la élite. Se trataría de una forma de solventar una disputa entre dos grupos por medio de un combate singular de sus líderes ${ }^{12}$, los cuales reafirmarían también su poder frente a su propia comunidad. En otras palabras, aquellos líderes capitalizarían la defensa de la comunidad en general y la de sus intereses personales en particular, ya que muy probablemente ellos eran quienes controlaban los medios productivos, lo que a su vez les permitía situarse en la cúspide de la pirámide social. Esta relación entre las monomaquias y la élite parece verse respaldada no solo por el propio pomo, sino también por la existencia de otro combate singular en un broche de cinturón damasquinado en plata en la sepultura II del túmulo Z de la Zona I de La Osera (Cabré, 1937, lám. XXIII; Baquedano y Escorza, 1996, p. 31), una tumba con armamento de guerrero y muy suntuosa.

Los combates singulares también son recogidos por las fuentes clásicas y los vinculan con la clase dominante. En esta zona nos interesan dos episodios relacionados con la conquista romana de la península ibérica. El primero de ellos narra los funerales de Viriato en los que

Tras haber adornado a Viriato del modo más esplendoroso le prendieron fuego sobre lo alto de una pira y le inmolaron numerosas víctimas y, por secciones, la infantería y la caballería, corriendo alrededor del cadáver, armados iban entonando cánticos al modo bárbaro y todos se sentaron en torno a él hasta que el fuego se extinguió. Una vez concluido el ceremonial

12 Cuando hablamos de líderes nos referimos a posesores de ganado y señores de los rebaños trashumantes como está bien demostrado en el mundo vetón (p. e. Álvarez-Sanchís, 1999; Sánchez-Moreno, 1998, 2000; Salinas, 2010, pp. 100-101) y que nosotros hemos intentado demostrar y razonar para el resto de la meseta norte en nuestro trabajo (De Pablo, 2018, pp. 567-581). De ser así, es lógico que fueran ellos quienes protagonizaran estos enfrentamientos para defender frente a otros señores del ganado su posición en determinados aspectos como la defensa de pasos serranos o control de determinados pastos. iniciaron un certamen de combates singulares sobre su tumba (Apiano, Iber, 75).

El segundo de ellos, más relacionado aún con el pomo que tratamos por haber ocurrido en territorio vacceo, sucedió en el año 151 a. C. cuando el ejército Lúculo, apostado frente a las murallas de Intercatia, veía cada día como

un bárbaro salía con frecuencia de la ciudad a caballo y se situaba en medio de los dos ejércitos. Vestía armas ostentosas y desafiaba en combate singular a cualquier romano que quisiera enfrentársele. Nadie respondía a su desafío y con muecas de burla se retiraba ejecutando una figura de danza. La escena se repitió numerosas veces hasta que Escipión, a pesar de su edad juvenil, se sintió dolido y saltando al campo de batalla afrontó el combate individual. Era de estatura pequeña pero la Fortuna le llevó a vencer al megalon andra, al enorme varón (Apiano, Iber, 53, traducción R. Olmos, 2003).

En conclusión, aunque no son muy abundantes las referencias alusivas a monomaquias o combates singulares, tanto la iconografía como las fuentes clásicas documentan sobradamente estos enfrentamientos en el territorio de estudio, lo que hace de las dos representaciones del pomo, ya no un unicum o imagen excepcional sino un documento más para la interpretación de la vida e ideología de la élite vaccea y prerromana meseteña en general.

Finalmente, interpretamos los caballos como la montura de uno de los dos guerreros que aparecen luchando en cada combate singular, concretamente vinculamos cada caballo con el guerrero que le da la espalda y por ende está más cerca del animal. A este respecto sabemos que los guerreros cuando entablaban combate descabalgaban de su montura para luchar a pie (Quesada, 1998, pp. 171-173; Sánchez-Moreno, 2005, p. 249; Salinas, 2010, pp. 138-139), a sabiendas del valor del caballo en todos los sentidos. Ello se ha visto respaldado en la cuenca del Duero por representaciones iconográficas, tales como la de la roca 3 de Vermelhosa en Foz Coa, donde uno de los dos guerreros que se enfrentan a pie está unido a un caballo por medio de una correa (Luis, 2016, fig. pp. 65 y 69). A este respecto, también es muy ilustrativo el texto de Polibio cuando habla de los celtiberos y su trato a estos animales en batalla, algo que nos ayuda a entender, además, la posición de los dos animales, orientados hacia el guerrero que estaría combatiendo: 
Esto tienen de particular los celtíberos en la guerra: cuando ven que sus infantes ceden, descabalgan y dejan los caballos dispuestos en formación; al efecto disponen unos pequeños clavos al extremo de las riendas, los que clavan en el suelo enseñando a los caballos a no moverse de la fila hasta que ellos vuelven y arrancan los clavos (Polibio, fr. 95).

Una vez reconocidas las figuras representadas y buscados los paralelos en el registro arqueológico, en un primer apartado, e interpretadas cada una de las representaciones haciendo uso, no solo del registro arqueológico, sino también de los textos clásicos, en una segunda parte, comenzamos entretejer todas esas interpretaciones en la búsqueda de una lectura global, que a continuación exponemos.

\section{UNA LECTURA GLOBAL DE LA ESCENA}

Llegados a este punto, hemos de reconocer que, aunque podamos coincidir parcialmente con Sanz en la identificación de los animales representados, no compartimos su lectura hecha de las tres esferas -lo sagrado, lo guerrero y lo productivo-. Las interpretaciones de la decoración figurativa del pomo no coinciden ya que nosotros no vemos ningún elemento productivo, dado que los animales representados no son cerdos sino jabalíes, que son una pieza cinegética. De la misma manera, aquellas gallinas o perdices que ve Sanz a nuestros ojos son buitres y las posibles cabras las vemos como equinos. Por su parte, la esfera sagrada existe, pero no separada de ese aspecto guerrero sino completamente vinculada. No creemos por tanto que, como dice Sanz (1997, p. 440), estas representaciones sean elementos yuxtapuestos con algunas conexiones, sino una escena con afán narrativo en la que todo está interconectado, incluso la posición de cada figura no parece ser casual. Nuestra interpretación de este unicum de la iconografía vaccea, como hemos visto, pasa por considerar aspectos de diversa índole, pero siempre relacionados con la práctica de las armas y que tienen como punto de encuentro un miembro de la aristocracia vaccea. El mensaje es un fiel reflejo de la ideología de ese personaje situado en lo más alto de la jerarquía social con respecto a la guerra y las armas, y la trascendencia que estas tienen en la sociedad.

Consideramos que la escena hace uso de una serie de símbolos e iconos reconocibles, valorados y compartidos por toda la sociedad y que el poseedor del arma hizo uso de ellos para mostrar su poder y posición privilegiada tanto económica como, sobre todo, social. La escena está representada en lo que entendemos es el reverso del arma, un lugar íntimo, lo que también nos podría indicar que, aun siendo una decoración para ser exhibida, las figuras ahí representadas tenían un significado personal muy fuerte para su poseedor y la representación de ciertos símbolos no solo respondió a una finalidad ostentatoria.

Nuestra interpretación de la escena del pomo en conjunto pasa por rescatar nuevamente el episodio de Intercatia del 151 a. C. y sus consecuencias. Si bien, esta vez recogeremos un texto de Plinio, que nos informa, ya no del combate singular entre Escipión Emiliano y el guerrero intercatiense, sino del proceder del hijo de este último, tras la derrota a manos del romano:

Cuentan los autores que aquel intercatiense a cuyo padre mató en un desafío Escipion, llevaba un sello en el que estaba grabado este combate. De ahí el chiste tan divulgado de Estilon Preconio, que preguntaba lo que habría hecho si su padre hubiese dado muerte a Escipion (Plinio, N. H. XXXVII, 4, 9, traducción García Bellido, 1987).

Como vemos, después de la derrota del vacceo de Intercatia a manos de Escipión, episodio narrado por muchos autores clásicos (Tito Livio, Per, 48; Polibio, XXXV, 5, 1-2; Apiano, Iber, 53; Orosio, IV, 21, 2), el hijo del intercatiense, lejos de ver esto como una deshonra, se hizo grabar la representación de ese hecho en un anillo o sello. Algo que, según Plinio, despertó las bromas del gramático Estilón Preconio, preguntándose ¿Qué es lo que hubiera hecho (el hijo) si Escipión hubiera sido muerto por su padre? (Olmos, 2003, p. 96). Lo que nos lleva a pensar que para el hijo del vacceo la derrota no era, ni había supuesto, un estigma para él sino todo lo contrario, era algo para recordar y enorgullecerse, es decir, toda una hazaña. Las bromas de Estilón Preconio nos revelan, además, que representar una derrota no era algo entendido por la mentalidad romana, por el contrario, en el mundo vacceo todo indica que la representación del coraje o, mejor, del sacrificio de una persona en beneficio de la comunidad no solo se entendía, sino que era valorado e incluso venerado.

Al hilo de esto, proponemos la lectura de esas dos monomaquias situadas en los extremos del pomo como los combates singulares en los que antepasados del dueño del arma lucharon y fueron derrotados. Ello explicaría, en primer lugar, la existencia de un caballo sin montura con el que pudieron llegar esos contendientes caídos al combate, quienes previamente al lance lo habrían descabalgado, mostrando asimismo que pertenecen a una clase privilegiada por la posesión de este animal. Asimismo, la postura en reposo del animal parece recordarnos al pasaje anteriormente citado de Polibio (fr. 95). A este respecto son varias las tumbas en la necrópolis de Las Ruedas las que respal- 
dan arqueológicamente la existencia del vínculo entre estatus y la posesión de un caballo, caso de las tumbas 75, 109 o 172 (Sanz et al., 2003, pp. 173-196, fig. 4 y 7; Sanz, 2007, pp. 83-86; Sanz et al., 2009, pp. 63-69). En segundo lugar, vemos a un buitre que tiene su pico en dirección al círculo reticulado de la deidad, como si ya hubiera dado cuenta del cuerpo de guerrero y actuado como trasmisor o psicopompo del alma entre la esfera terrenal, donde se había desarrollado el combate, y la celestial, donde esperaba la divinidad. De esta manera, el poseedor del puñal daba a entender que sus antepasados gozaron de un ritual funerario reservado solo a unos pocos. Como un tercer elemento, están las dos representaciones de la deidad dispuestas en horizontal y orientadas hacia las dos monomaquias, en un claro posicionamiento de protección del cuerpo y el alma del guerrero, interpretándose además el círculo reticulado como el lugar donde se recibiría o tomaría el alma del difunto. Quedaría una tercera representación de la deidad dispuesta en vertical hacia la hoja de la daga, en una evidente intención de proteger, ahora sí, los enfrentamientos futuros del portador del puñal. Llegados a este punto, la falta del círculo reticulado en esta hipóstasis de la divinidad ${ }^{13}$, se explicaría porque, de momento, el portador del puñal todavía no había sido acogido por ella.

La representación de esas dos personas caídas en un combate es, además, una forma de honrar a sus antepasados, quienes muy probablemente, a su muerte en esos combates, legaron esa posición económica y socialmente privilegiada al poseedor del puñal ${ }^{14}$. También es una forma de conectar con ellos afianzando o demostrando su pertenencia a un linaje o familia aristocrática.

Por supuesto, los jabalíes aquí representados no vendrían a ser más que la forma de simbolizar y trasmitir la valentía, la fuerza y el ardor de los dos combatientes a los que se quiere glorificar (sus dos antepasados caídos en combates anteriores) además de la de él mismo, el dueño de tan magnífica daga. Pues si no se utilizara un símbolo como el jabalí para reflejar ese comportamiento ejemplar en el combate difícilmente se podría trasmitir ese valiente proceder en una sociedad ágrafa. Finalmente, el cánido representado en

13 En este sentido pudiéramos pensar que la existencia de lobos en otros puñales, como el broche de tipo Monte Bernorio recogido en prospección de la necrópolis de Piñuelas y mencionado arriba, pudiera responder a una finalidad profiláctica de ese mismo dios-lobo.

14 Pues en este sentido no creemos que en las sociedades meseteñas prerromanas las armas fueran un medio de acceder o alcanzar la cúspide social, sino más bien la forma de mantener y simbolizar el poder. el canto del pomo, desplazado de la escena principal, bien podría ser un perro, a nuestro juicio, una forma de simbolizar y demostrar la fidelidad del propietario del puñal a sus antepasados y el respeto hacia su legado, el cual también reivindicaba.

En definitiva, proponemos e interpretamos el pomo del puñal como una evidencia arqueológica de un hecho solo conocido hasta el momento por la literatura clásica. Similar a lo que fueron en su momento las cerámicas numantinas -con representaciones de grandes aves y hombres muertos armados-a los textos clásicos de Claudio Eliano y Silio Itálico -que narraban la exposición a los buitres de los guerreros caídos en combate-. Representaciones, tanto las cerámicas numantinas como el pomo que ahora tratamos, difíciles de interpretar si no hubieran existido esos pasajes tan explícitos de los autores clásicos. Así, la coincidencia entre el texto pliniano (N. H. XXXVII, 4, 9) y la iconografía estudiada no solo reside en que se represente un combate singular, sino en que se haga en un objeto personal e íntimo de gran valor económico - un anillo o sello en un caso y el pomo de un puñal en otro-, en que quien lo demande sea un miembro de la élite y en que quien lo promueva sea un descendiente, que además vincularía la derrota al orgullo y el honor y no a la deshonra ${ }^{15}$.

\section{A MODO DE CONCLUSIÓN}

No cabe duda de que los puñales Monte Bernorio, tal y como después lo serán en la meseta norte los puñales de enmangue en espiga y los de filos curvos (De Pablo, 2010; De Pablo, 2012), no solo fueron armas sino objetos de prestigio, indicadores de estatus y muy probablemente símbolos de pertenencia a una clase o grupo privilegiado ${ }^{16}$. Además de todo esto, creemos que el puñal que ahora tratamos fue un objeto de reconocimiento, veneración y culto a los antepasados, tal y como hemos tratado de demostrar, así como, un objeto que demostró no solo la pertenencia de su poseedor a un grupo privilegiado, sino que este se encontraba en la misma cúspide de ese grupo y por lo tanto de la jerarquía social.

Una vez expuesta nuestra hipótesis sobre el significado de la escena en cuestión se nos plantean algunas

15 Si bien es cierto que la iconografía del pomo es, a nuestro juicio, un reflejo de lo que nos relata Plinio en su pasaje, tampoco es menos cierto que igualmente lo es del texto de Claudio Eliano sobre la exposición de los guerreros muertos a los buitres y el papel de estos como transmisores del alma.

16 La dimensión socioeconómica de los puñales prerromanos merece una reflexión en profundidad que excede los límites y objetivos de este trabajo. 
preguntas sobre la vida, valor y tiempos de la pieza en sí misma. Una de las preguntas que se formularon casi desde el momento de su descubrimiento fue la de cuantos tiempos ${ }^{17}$ pudo tener el puñal hasta su amortización, a lo que primero C. Sanz (1997, p. 440) y después F. Romero (2010, pp. 486-488) propusieron dos. Sin decantarnos por ninguna opción en concreto, en futuros trabajos habremos de responder si se trata de un puñal realizado de una sola vez, tanto la hechura de la propia daga como la decoración, y amortizado por su primer poseedor, con lo que tendríamos un solo tiempo; una segunda opción sería que la manufactura del puñal y de la iconografía fueran de un solo momento y que la pieza, una vez se hubiera transformado en un objeto de veneración y heroización de los antepasados, se convirtiera en una reliquia que hubo de haber amortizado un descendiente del creador, con lo que estaríamos hablando de dos tiempos ${ }^{18}$; una última opción sería la de los tres tiempos, en los que la factura del puñal, la ejecución de la escena y la amortización en tumba fue hecha por tres personas diferentes. En este sentido, si se tratara de una pieza con dos o tres tiempos, habríamos de calificar esta y el broche como reliquias y, al hilo de ello, nos deberíamos hacer una nueva pregunta: ¿faltan realmente la vaina y el resto de la daga en la tumba por un motivo de conservación, o al tratarse de una reliquia las piezas fueron cuidadosamente seleccionadas?

Hoy día, es difícil responder a estas preguntas. Esperamos pues que nuevos hallazgos, trabajos y aportaciones permitan avanzar no solo en el estudio de esta pieza en concreto, sino también en el de las armas, la simbología y las creencias del mundo vacceo.

\section{BIBLIOGRAFÍA}

Abarquero Moras, F. J. (2006-2007). "Simbolismo cenital en el mundo vacceo a propósito de un recipiente de cerámica de las Eras de San Blas (Roa, Burgos)". Boletín del Seminario de Estudios de Arte y Arqueología, Arqueología, LXXII-LXXIII, pp. 183-209.

Abarquero Moras, F. J. y Palomino Lázaro, A. L. (2012). Arquitectura doméstica y mundo simbólico en la ciudad vaccea de Rauda. La "Casa del Sótano" en las Eras de San Blas (Roa, Burgos). Burgos: Academia Burguense de Historia y Bellas Artes. Institución Fernán González.

Alfayé Villa, S. (2010). "Iconografía vaccea: una aproximación a las imágenes del territorio vacceo". En: Romero,

17 Cuando hablamos de tiempos nos referimos a momentos en los que la pieza es sujeto de una acción sobre ella, no de la trasmisión de generación a generación.

18 En relación a la existencia de dos tiempos también podría haberse dado la posibilidad de que el puñal se manufacturara en un primer momento y después se realizara la decoración y amortización en tumba por una segunda persona.
F. y Sanz, C. (Eds.), De la Región Vaccea a la Arqueología Vaccea. Valladolid: CEVFW de la Universidad de Valladolid (Vaccea Monografías, 4), pp. 547-573.

Almagro-Gorbea, M., Ballester, X. y Turiel, M. (2017). "Tésera celtibérica con 'lobo cenital' procedente de Burgos". Boletín del Seminario de Estudios de Arte y Arqueología, Arqueología, LXXXIII, pp. 57-185.

Álvarez Sanchís, J. R. (1990). "Los verracos del Valle del Amblés (Ávila): del análisis espacial a la interpretación socio-económica". Trabajos de Prehistoria, 47, pp. 201-233. DOI: https://doi.org/10.3989/tp.1990.v47.i0.560

Álvarez Sanchís, J. R. (1999). Los Vettones. Bibliotheca Archaeologica Hispana, 1. Madrid: Real Academia de la Historia.

Baquedano, I. y Escorza, C. M. (1996). "Distribución espacial de una necrópolis de la II Edad del Hierro: La Zona I de La Osera en Chamartín de la Sierra, Ávila". Complutum, 7, pp. 175-194.

Blanco García, J. F. (1997). "Zoomorfos celtibéricos en perspectiva cenital. A propósito de los hallazgos de 'Cauca' y el castro 'Cuesta del Mercado' (Coca, Segovia)”. Complutum, 8, pp. 183-203.

Blanco García, J. F. (2013). "Animales domésticos en la iconografía vaccea”. Vaccea Anuario 2012, n. 6, pp. 54-60.

Blanco García, J. F. (2014). "La naturaleza salvaje en el mundo vacceo: imagen y símbolo". Sautuola, XIX, pp. 219-234.

Cabré Aguiló, J. (1931). “Tipología del puñal, en la cultura de "Las Cogotas". Archivo Español de Arte y Arqueologia, XXXI, pp. 221-241.

Cabré Aguiló, J. (1937). "Broches de cinturón de bronce damasquinados con oro y plata". Archivo Español de Arte y Arqueología, XIII, pp. 93-126.

De Griño Frontera, B. (1989). Los puñales de tipo Monte Bernorio- Miraveche: Un arma de la Segunda Edad del Hierro en la Cuenca del Duero. BAR International Series, 504. Oxford.

De Pablo Martínez, R. (2010). "Los Puñales de Filos Curvos en el Duero Medio y Alto Ebro. A propósito de los llamados tipo La Osera y Villanueva de Teba”. En: Romero, F. y Sanz, C. (Eds.), De la Región Vaccea a la Arqueología Vaccea. Vaccea Monografías, 4. Valladolid: CEVFW de la Universidad de Valladolid, pp. 363-396.

De Pablo Martínez, R. (2012). "El pugio romano: nuevos datos para el estudio de su origen". Gladius, XXXII, pp. 49-68.

DOI: https://doi.org/10.3989/gladius.2012.0003

De Pablo Martínez, R. (2018). Armamento y guerra durante la Segunda Edad del Hierro en la Cuenca central del Duero y el Alto Ebro: los puñales como armas y simbolos. Universidad de Valladolid, Tesis doctoral inédita.

Fernández Gómez, F. (1973). "Santuario de Postoloboso (Candeleda, Ávila)", Noticiario Arqueológico Hispánico, Arqueología, 2, pp. 169-270.

Fernández Gómez, F. (1995). "La Edad del Hierro". En: Mariné, M. (Coord.), Historia de Ávila I, Prehistoria e Historia Antigua. Ávila: Institución "Gran duque de Alba", pp. 103-269. 
Filloy Nieva, I. y Gil Zubillaga, E. (1997). "Las armas de las necrópolis celtibéricas de Carasta y La Hoya (Álava, España): Tipología de sus puñales y prototipos del pugio". Journal of Roman Military Equipment Studies, 8, pp. 137-150.

García Bellido, A. (1987). La España del siglo primero de nuestra era (según P. Mela y C. Plinio). Madrid: Espasa-Calpe.

Lión Bustillo, M. C. (1987) “Copas con anillas en la provincia de Palencia”. Publicaciones de la Institución Tello Téllez de Meneses, 56, pp. 15-30.

Luís, L. (2016). "As gravuras da Idade do Ferro no Vale do Coa”. Vaccea Anuario, 9, 2015, pp. 60-70.

Martín Valls, R. (1990). "Los simpula celtibéricos". Boletín del Seminario de Estudios de Arte y Arqueología, Arqueología, LXI, pp. 144-169.

Olmos Romera, R. (2003). "Combates singulares: lenguajes de afirmación de Iberia frente a Roma". En: Tortosa, T. y Santos, J. A. (Eds.), Arqueología e Iconografia, indagar en las imágenes. Bibliotheca Italica, Monografías de la EEHA en Roma, $n^{\circ} 26$. Roma: Escuela Española de Historia y Arqueología en Roma, pp. 79-98.

Quesada Sanz, F. (1998). "Aristócratas a caballo: la existencia de una verdadera caballería en la cultura ibérica: dos debates conceptuales diferentes". En: Aranegui, C. (Ed.), Actas del Congreso internacional: Los Iberos, principes de Occidente. Barcelona: 1998, pp. 169-183.

Romero Carnicero, F. (1999). "El vaso de los guerreros de Numancia. Aproximación a su lectura iconográfica". Revista de Soria, $\mathrm{n}^{\circ} 25$, pp. 51-65.

Romero Carnicero, F. (2010). "Las Representaciones zoomorfas en perspectiva cenital. Un estado de la cuestión". En: Romero, F. y Sanz, C. (Eds.), De la Región Vaccea a la Arqueología Vaccea. Vaccea Monografías, 4. Valladolid: CEVFW de la Universidad de Valladolid, pp. 467-545.

Romero Carnicero, F. y De Pablo Martínez, R. (2019). "Producciones cerámicas con decoración excisa en el Alto Ebro". En: Sanz, C. y Blanco, J. F. (Eds.), Producciones excisas vacceas. Antecedentes y pervivencias. Vaccea Monografías, 7. Valladolid: CEVFW de la Universidad de Valladolid, pp. 101-138.

Salinas de Frías, M. (2010). "Sobre algunos textos clásicos referentes a la caballería de los celtíberos y al simbolismo de sus armas". Gladius, XXX, pp. 137-157. DOI: https://doi.org/10.3989/gladius.2010.0007
Sánchez Moreno, E. (2005). "Caballo y Sociedad en la Hispania Céltica: del poder aristocrático a la comunidad política". Gladius, XXV, pp. 237-264.

DOI: https://doi.org/10.3989/gladius.2005.30

Santos, F., Sastre, J. C., Soares de Figueiredo, S., Rocha, F., Pinheiro, E. y Dias, R. (2012). "El sitio fortificado del Castelinho (Felgar, Torre de Moncorvo, Portugal). Estudio preliminar de su diacronía y las plaquetas de piedra con grabados de la Edad del Hierro". Complutum, 2012, Vol. 23 (1), pp. 165-179.

DOI: https://doi.org/10.5209/rev_cmpl.2012.v23.n1.39536

Sanz Mínguez, C. (1990) "Metalistería prerromana en la cuenca del Duero. Una propuesta secuencial para los puñales de tipo Monte Bernorio". Boletín del Seminario de Estudios de Arte y Arqueología, Arqueología, LVI, pp. 170-188.

Sanz Mínguez, C. (1997). Los vacceos: cultura y ritos funerarios de un pueblo prerromano del valle medio del Duero. La necrópolis de Las Ruedas, Padilla de Duero (Valladolid). Arqueología en Castilla y León, Memorias 6. Valladolid: Junta de Castilla y León.

Sanz Mínguez, C. (2007). "El equites de la tumba 109: la confirmación de espacios reservados para la elite en el cementerio de Las Ruedas". En: Sanz, C. y Romero, F. (Eds.), En los extremos de la región vaccea. León: Caja España, pp. 83-86.

Sanz Mínguez, C. (2010). "Armamento vacceo". En: Romero, F. y Sanz, C. (Eds.), De la Región Vaccea a la Arqueología Vaccea. Vaccea Monografías, 4. Valladolid: CEVFW de la Universidad de Valladolid, pp. 319-361.

Sanz Mínguez, C. y Blanco García, J. F. (2015). "Figuración y abstracción en el universo mental vacceo. El bestiario en Pintia (Padilla de Duero/Peñafiel, Valladolid)". Vaccea Anuario 2014, n. 8, pp. 32-40.

Sanz Mínguez, C., Gallardo Miguel, M. A., Velasco Vázquez, J y Centeno Cea, I. (2003). "La tumba 75 de Las Ruedas, primer testimonio arqueológico de la elite ecuestre vaccea". En: Sanz, C. y Velasco, J. (Eds.), Pintia. Un oppidum en los confines orientales de la región vaccea. Valladolid: Universidad de Valladolid, pp. 173-196.

Sanz Mínguez, C., Romero Carnicero, F., Górriz Gañán, C. y De Pablo Martínez, R. (2009). El vino y el banquete en la Ribera del Duero durante la Protohistoria. Vaccea Monografías, 3. Valladolid: CEVFW de la Universidad de Valladolid.

Schüle, W. (1969). Die Meseta-Kulturen der Iberischen Halbinsel. Berlin: Madrider Forschungen, 3. 